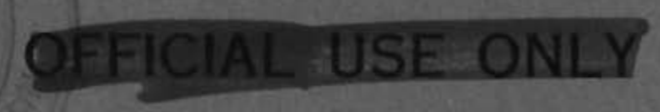

BNWL - 247

6 ?-

\title{
PACIFIC NORTHWEST LABORATORY MONTHLY ACTIVITIES REPORT MARCH 1966
}

\section{DEVELOPMENT} REPORT

\author{
on \\ AEC DIVISION \\ of \\ BIOLOGY AND MEDICINE PROGRAMS
}

APRIL, 1966

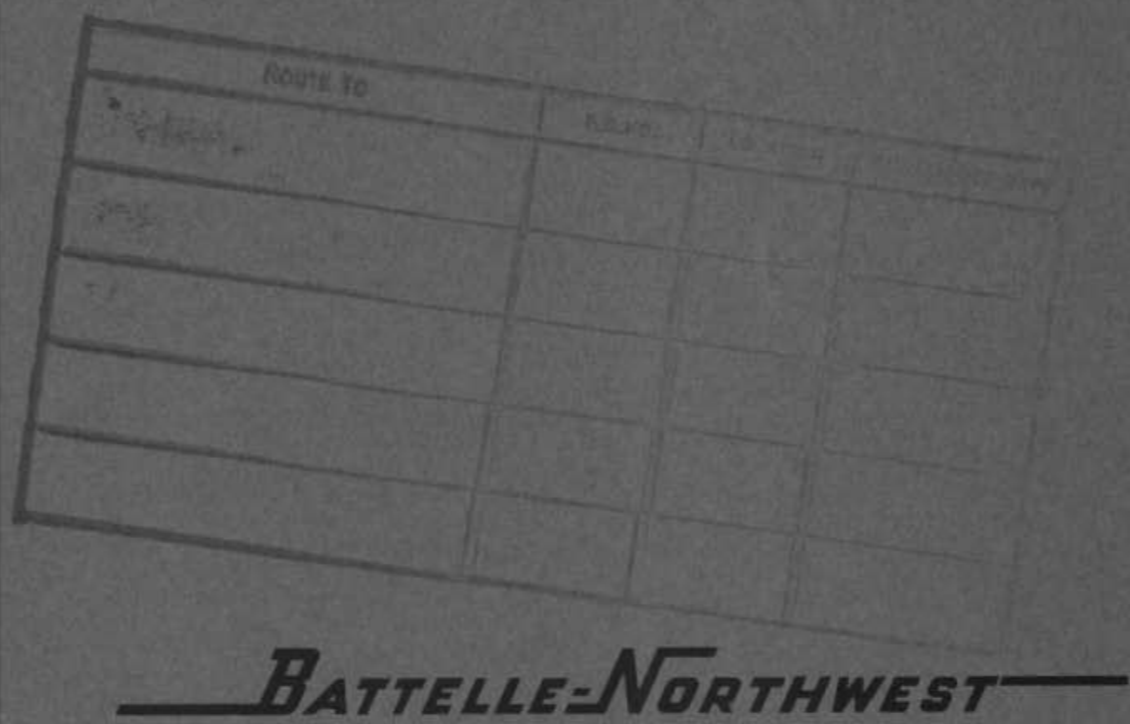

BATTELLE MEMORIAL. INSTITUTE / PACIFIC NORTHWEST LABORATORY 


\section{LEGAL NOTICE}

This report was prepared as an account of Government sponsored work. Neither the United States, nor the Commission, nor any person acting on behalf of the Commission:

A. Makes any warranty or representation, expressed or implied, with respect to the accuracy, completeness, or usefulness of the information contained in this report, or that the use of any information, apparatus, method, or process disclosed in this report may not infringe privately owned rights; or

B. Assumes any liabilities with respect to the use of, or for damages resulting from the use of any information, apparatus, method, or process disclosed in this report.

As used in the obove, "person acting on behalf of the Commission" includes any employee or contractor of the Commission, or employee of such contractor, to the extent that such employee or contractor of the Commission, or employee of such contractor prepares, disseminates, or provides access to, any information pursuant to his employment or contract with the Commission, or his employment with such contractor.

\section{PACIFIC NORTHWEST LABORATORY}

RICHLAND, WASHINGTON

operated by

BATTELLE MEMORIAL INSTITUTE

for the

UNITED STATES ATOMIC ENERGY COMMISSION UNDER CONTRACT AT(45-1)-1830 


\title{
PACIFIC NORTHWEST LABORATORY
}

MONTHLY ACTIVITIES REPORT

MARCH 1966

\author{
on \\ AEC Division \\ of
}

Biology and Medicine Programs

S. L. Fawcett - Director

D. C. Worlton

H. A. Kornberg

M. T. Walling

H. Harty

W. D. Richmond

F. W. Albaugh - Associate Director

R. S. Paul - Associate Director

A. R. Keene

J. J. Fuquay

Manager, Applied Physics and Electronics

Manager, Biology

Manager, Chemistry

Manager, Engineering Development

Manager, Engineering Services

Manager, Environmental Health and Engineering

Manager, Environmental and Radiological Sciences

E. R. Astley

D. R. de Halas

Manager, FFTF Project

C. A. Bennett

Manager, Materials

Manager, Mathematics

J. J. Cadwell

Manager, Metallurgy

F. G, Daw son

Manager, Reactor Physics

April, 1966

\section{NOTICE: PRELIMIN ARY REPORT}

This report contains information of a preliminary nature prepared in the course of work under Atomic Energy Commission Contract AT(45-1)-1830. This information is subject to correction or modification upon the collection and evaluation of additional data. 


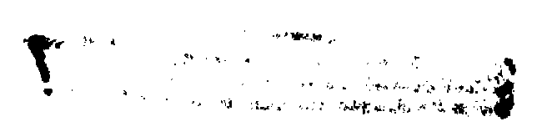


PACIFIC NORTHWEST IABORATORY

MONTHLY ACTIVITIES REPORT

MARCH 1966

AEC DIVISION OF BIOIOGY AND MEDICINE PROGRAMS - R。S。 PAUL

RADIATION EFFECTS - GENERAL

MECHANISM AND TREATMENT OF GASTROINTESTINAL RADIATION EFFECTS -

M.F. Sullivan

Histopathologic analysis of isolated gut segments from irradiated rats that were used to study absorption by an in vitro technique indicated that radiation damage to the mucosa and mucosal function were not closely related. The in vitro bioelectric and transport characteristics were not seriously influenced unless severe morphologic damage occurred.

RESPONSE OF INSECTS TO RADIATION - F。P. Hungate

In an earlier experiment with flour beetles, the black-body color mutant, Sooty, appeared more DDT resistant than the wild strain, Brazil cI, and was reproductively more fit when stressed with DDT plus X-radiation. To verify this observation and to determine whether the resistance was clearly associated with body color, a series of new tests were initiated making use of specific crosses of the Sooty mutant with other strains. Data from these tests are not yet available.

An interim analysis was completed by the Mathematics Department relative to a continuing experiment designed to assess the effects of co60 irradiation of flour beetles.

\section{TOXICITY OF RADIOFLEMENTS}

FACTORS AFFECTING THE TOXICITY AND METABOLISM OF RADIONUCLIDES M。F。Sullivan

Cesium-137 retention half-time in rats was decreased by increased dietary potassium or decreased ambient temperzture, confirming previous results obtained by others. Retention was followed in several tissues in the present study and found to decrease non-uniformly. This nonuniform decrease is being rechecked. 


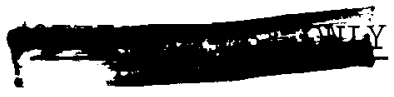

The uranium chelate of DTPA was tested as a radiopaque medium in pigs. Injection of this material killed pigs almost instantly from a calcium tetany. When calcium was injected with the agent the pigs lived, but there was not sufficient visualization of the venous system or bladder to merit its use. Similar compounds have been successful in dogs at lower metal dosages.

An analysis of data to compare dietary nuclide levels in rats injected with Cl4-chlorine and fed various levels of $\mathrm{Sr} 90$ was begun by the Mathematics Department.

FACTORS AFFECTING THE TOXICITY AND METABOLISM OF RADIONUCLIDES IN AQUATIC ORGANISMS - R. E. Nakatani

The concentration of $\mathrm{Zn} 65$ in various soft tissues of the freshwater clam, Anodonta nuttaliana, after eight days exposure to water containing $0.1 \mathrm{\mu Ci} / \mathrm{ml}$, was approximately eight times higher than after a one-day exposure. Relative concentrations in the various tissues did not change during the eight-day exposure. Concentrations after eight days exposure ranged from $5.2 \mu \mathrm{Ci} / \mathrm{g}$ in the gills to a low of $0.4 \mu \mathrm{Ci} / \mathrm{g}$ in the foot. Studies were initiated on normal histology and seasonal changes in glycogen and lipid content in Anodonta to obtain reference values for future experiments.

Salinity tolerance of the green shore crab, Hemigrapsus Oregonensis, was established for experiments planned to study the effect of salinity on uptake and retention of $\mathrm{Zn} 65$. In our laboratory environment, the crabs can be maintained in a healthy state for over four weeks at salinities ranging from $10 \%$ to $30 \%$, with the exception that females did not tolerate the low salinity of $10 \% / 00^{\circ}$ Blood samples showed that crabs are osmoregulatory. The blood of the 10 and $20 \%$ groups was hyperosmotic to the environment.

INHALATION STUDIES - W. J. Bair

Additional tests corroborated previously reported observations of increased levels of collagen precursors (protocollagen) in lungs of rats maintained on cyanide-treated drinking water for several months. However, based on weight and hydroxyproline content, the lungs of the cyanide drinking rats contained less acid-soluble collagen. Tentative evidence was obtained for the presence of a cyanide metabolite, 2-iminothiazolidine-4-carboxylic acid, in the extracted collagen from the cyanide-treated rats. 


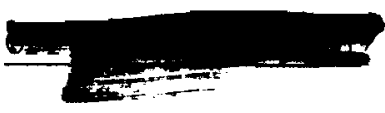

Among groups of 3 or 4 dogs that inhaled one of four different plutonium dioxide dusts, those exposed to the oxide prepared by calcining the oxalate at $350^{\circ}$ showed the greatest translocation and greatest rate of excretion in urine. Greater retention was observed among dogs that inhaled oxides produced by ignition of the stabilized delta metal at $450^{\circ} \mathrm{C}$, by slow oxidation of the pure metal in air at $123^{\circ}$, or by calcincing the oxalate at $950^{\circ} \mathrm{C}$. Inhalation of the latter oxide gave the lowest rate of translocation and excretion in both urine and feces.

SNPO AND SNAP BIOLOGICAL STUDIES - R. C. Thompson

Studies are in progress to develop methods for producing aerosols of large $\mathrm{Pu}^{238} \mathrm{O}_{2}$ particles for inhalation exposure of dogs.

Detection of Pu238 micro spheres retained in the GI tract of a pig by external bremsstrahlung counting or by passage of an ion chamber appears feasible. The plutonium lung counter developed by Radiological Physics can be adapted to detect a few particles inside a pig. Detection of a single particle requires increased shielding and counting time. An ion chamber rugged enough for passage through a pig and capable of detecting $1 \mathrm{mR}$ could be fabricated. A dummy ion chamber was passed 74 hours after administration via stomach tube.

Several attempts have been made at isolation of $\mathrm{Pu}$ particles from pig feces. Repeated sonication in a high density liquid system gave a very "hot" supernatant but did not free the particles from the debris. Use of a column of wax to clean and separate particles by means of zone melting awaits the acquisition of required equipment. None of the dye methods tried have enabled any easier visualization of the particles.

\section{MOLECULAR AND CELLULAR LEVEI STUDIES}

\section{CELIULAR REGUILATORY MECHANISMS - W。 Ho Matchett}

Further effort, toward perfecting the method of obtaining mutants of Neurospora which are unable to transport tryptophan, has apparently been fruitful. Using ethylmethane sulfonate as the mutagenic agent, conidia were selected which exhibit some properties expected of the desired mutants (e.g., normal growth on indole, greatly retarded growth on tryptophan). Appropriate physiological and genetic experiments, currently in progress, are needed for a precise identification of the lesion suffered by these isolates.

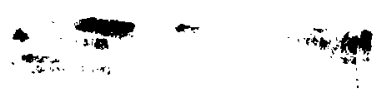


Extracts of mutant td 201 and td 141 of Neurospora were shown to catalyze the disappearance of indole when supplied with substrate quantities of pyruvate. If this involves the formation of a condensation product of indole and pyruvate (e.g., indole pyruvic acid) then this constitutes a reaction not previously described. This line of investigation will be continued to identify the product formed and the enzyme involved.

We have shown previously that in cells of Escherichia coli recovering from chloramphenicol poisoning, methionine enhances the rate of conversion of chloramphenicol ribonucleoprotein particles to 70 s ribosomes. We have now shown that methionine also enhances the absolute and relative rates of de novo synthesis of RNA in such cells. These results tend to substantiate the model which postulates a regulatory function for ribonucleoprotein particles in RNA synthesis.

\section{CHARACTERIZATION OF RADIATION-INDUCED FREE RADIAL REACTIONS IN AQUEOUS}

\section{SYSTEMS - D. R. Kalkwarf}

A Varian 6-MV electron accelerator, newly installed at ohio state University, was used to study the pulse radiolysis of water and aqueous solutions. In initial experiments with $0 . \mathrm{M} \mathrm{KOH}$ solutions, the transient optical absorption spectrum of a species postulated to be the ozonide radical-ion, $\mathrm{O}_{\overline{3}}$, was observed following microsecond pulses of 3-MV electrons. Using the optical absorbency of this species as a measure of its concentration, measurement of its reaction rates with other species can now be attempted.

Further experiments on the chemical protection of irradiated agarose jellies showed the value of mixtures of protective agents. Addition of both the food colorings, FD\&C Blue No. 1 and FD\&C Blue No.2, at concentrations of $4 \times 10-3 \mathrm{M}$ to $0.20 \%$ agarose jellies extended their liquefaction dose by a factor of 19. This can be compared with factors of 15 for either dyestuff used separately at $8 \times 10^{-3} \mathrm{M}$. The coenzyme, flavin mononucleotide, was also found to be an excellent protective agent for irradiated agarose jellies and a concentration of $5 \times 10^{-3} \mathrm{M}$ extended the liquefaction dose by a factor of 16 . Higher concentrations of this compound did not provide as much protection, however, indicating that the additive had weakened the jelly structure to be protected. 


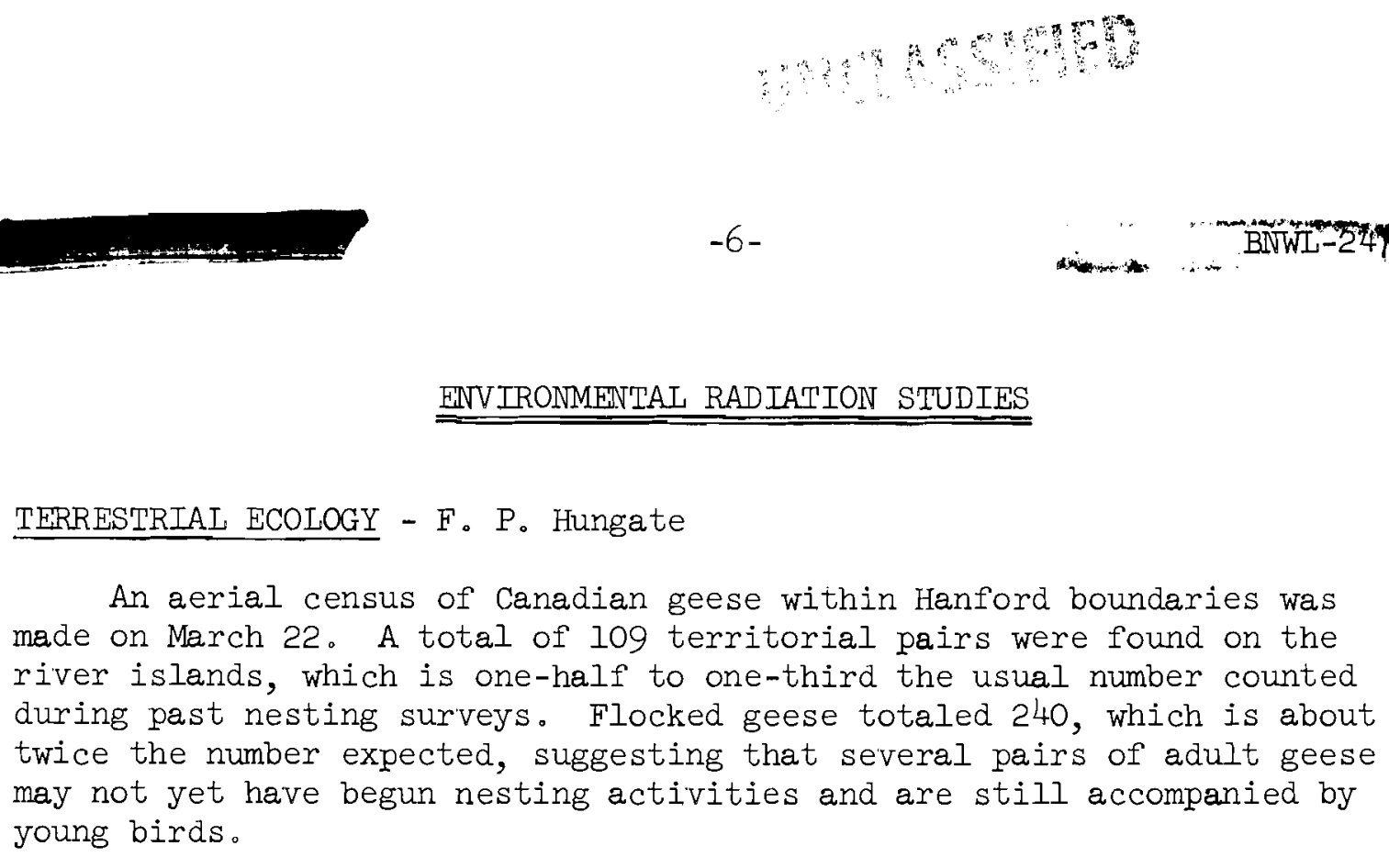

\section{PLANT UPTAKE OF RADIONUCLIDES - F. P. Hungate}

Autoradiographs of leaf cross-sections indicate the site of iodine penetration through the cuticle of begonia leaves is both spotty and at random. Autoradiograms of the exposed surface verified the apparent spotty uptake. This is suggestive that movement into the leaf may be through breaks in the cuticular surface rather than a direct penetration through the cuticle. Further evaluation will be required to verify this。

In previous tests to study the penetration of Il3.I through cuticular leaf surfaces, paraffin softened with vaseline was used to attach the $I^{13 l}$ source equipment to the leaf surface. Undesirably large amounts of Il 1 were absorbed into this ealing mixture. Further tests have shown that uptake of Il3l by paraffin is quite low, as anticipated, but uptake in vaseline was higher by nearly an order of magnitude. Clearly, the use of vaseline in this application is undesirable.

\section{DYNAMIC BALANCE OF RADIONUCLIDES IN THE COLUMBIA RIVER - $R$ 。 E。 Nakatani}

Preliminary examination of the data from February and March collections of river organisms showed, as expected, that plankton and periphyton were the most radioactive. The dominant gamma emitter in these organisms was Cr51. In the herbivores, filter feeders, and fish, Zn65 was the most abundant. Samples collected on February 15 contained appreciable amounts of Il31 resulting from a release of this isotope. Il3I was undetectable in the March 8 sampling.

Intact populations of the river-bottom community collected at $100-F$ Area were transferred to a site relatively free of reactor effluent to determine effective half-lives of biological retention in a natural environment. Preliminary data on the limpet, Fisherola nuttallii, indicated 
effective half-lives of $13,12,8,6,5,4$, and 3 days for $\mathrm{Zn} 95, \mathrm{Ru}{ }^{106}$, $\mathrm{Zn}^{65}$, I131, Co $60, \mathrm{P}^{32}$, and $\mathrm{Mn}^{54}$, respectively.

Studies on periphyton communities exposed in the laboratory to a controlled flowing system containing about $3 \mathrm{nCi} \mathrm{Zn} 65 / \mathrm{ml}$ indicate the importance of distinguishing between the living and non-living components of algae communities collected from the river. The living system accumulated $2.2 \mathrm{nCi} / \mathrm{mg}$ dry weight compared to $7.2 \mathrm{nCi}$ for the formalin-killed community. These values represent approximate concentration factors of 200 and 700, respectively.

EARTH SCIENCES - W. A. Haney

Consideration was given to methods for handling the irregularities of the Project boundaries, i.e., Columbia and Yakima rivers, intersection of basalt and water table along Rattlesnake Mountain, in the canonical form methods of functional fitting. Steps will include two one-dimensional fittings, from data obtainable from the Army Map Service, followed by use of degenerate regions in the canonical form.

A testing program is in progress to evaluate the effectiveness of several different mathematical functions in describing three-dimensional surfaces. At the outset of the program it became obvious that round-off error was causing orthogonalization problems in GENORO when using the canonical form and harmonic polynomials. A double precision program was introduced into GENORO which reduced round-off error and improved orthogonalization problems, thereby making it possible to obtain a better fit of the data.

An important geologic feature was revealed by the recently constructed Gouguer gravity map. The anomalies on the Hanford Project are predominantly near - $50 \mathrm{milligals}\left(10^{-3} \mathrm{~cm} / \mathrm{sec}^{2}\right)$. These values are the least negative of published gravity data for the area covered by the columbia basalt flows. This indicates that the Hanford area is probably underlain by the greatest thickness of basalt flows in the Columbia Plateau. The information further enhances the value of Rattlesnake Mountain as a potential geophysical site.

\section{TEMPERATURE EFFECTS ON METABOLISM OF AQUATIC ORGANISMS}

Work was started on the isolation of ribosomes from livers of trout acclimated for four weeks to $5,11.5$ and $18^{\circ} \mathrm{C}$. The technique employed is a modification of that used for rat livers. These ribosome preparations will be used to investigate acetate incorporation as a function of temperature acclimation. 
Work continued on the development of assay procedures for acid phosphatase in fish liver and other tissues. We are now in a position to obtain useful data on the levels of this enzyme in fish acclimated to various temperatures, which hopefully can be correlated with the morphological changes noted previously.

MODELS FOR THE PREDICTION OF THE TRANSPORT OF RADIONUCLIDES - R. J. Wood

Specifications were formulated for a computer program of a multicompartment model for the uptake and retention of radioactive isotopes by a biological system.

\section{ATMOSPHERIC RADIOACTIVITY AND FALLOUT}

\section{RADIOISOTOPES AS PARTICLES AND VOLATILES - L. C. Schwendiman}

Non-sphericity of particles generated with the spinning disc aerosol generator was traced to charge neutralization occurring too late in the drying period of the particle subsequent to droplet formation. These charges are neutralized by injecting large numbers of ions of both signs into the airstream carrying the evaporating droplets. When the particles dry too thoroughly before the charge is neutralized, the final particles take non-spherical shapes such as pear shape, egg shape, rough surfaced spheres, and so on.

Operation of the ion generator for dissipating charges was studied to determine the settings for maximum ion current. The ion generator was shown to be adequate for neutralizing the charges; however, oddshaped particles would still form. Somewhat slower drying particles were formed by increasing the fraction of uranine in the alcoholic feed solution of methylene blue from 0.6 to 0.7 . Although this adjustment and optimum operation of the ion generator resulted in generation of spherical particles, the specific changes in operational variables which had occurred and which led to formation of non-spherical particles were not identified.

Design was largely completed for a new high speed spinning disc aerosol generator and some of the fabricated parts were made available. Certain changes from current designs should improve the capability of the instrument. A higher speed disc drive and down-flow of carrying air should permit better control of sizes and drying. 
ATMOSPHERIC SCIENCES - C. L. Simpson

The Rimrock Lake test site produced three more scavenging tests in snow February 28-March 1 and five mor tests in rain March 8-9, 1966, for a total of 18 offsite tests this season. These were multiple-tracer tests, using bromine and iodine gas and nonradioactive strontium, scandium, cesium and iodide particles. Successful field use of these particulate tracers encourages their consideration in gaseous-particulate deposition tests, in diffusion tests for several stack heights, in meso- and synopticscale trajectory studies and for in-cloud scavenging tests.

On-site scavenging tests, PUREX-4 and -6 yielded washout coefficients of $3.2 \times 10^{-4}$ and $4.2 \times 10^{-4} \mathrm{sec}^{-1}$ in rains of 0.52 and $0.87 \mathrm{~mm} \mathrm{hr}^{-1}$, respectively, for inorganic iodine. These coefficients are an order of magnitude high according to the simple theory of molecular diffusion applied to falling waterdrops. It is highly unlikely that contamination or experimental error could produce the same discrepancy for these tests when conducted and analyzed on separate days. After carefully checking the stack gas sampling techniques and finding nothing erroneous, it is necessary to conclude that the process iodine is not scavenged according to simple theory. It is believed that enhancement of the scavenging may result from concensing water droplets in the rather moist stack gases as they mix with the atmosphere. Unpublished private communications from Owe Berg recognize such processes in scrubbers. Comparison of the PUREX test results to the Rimrock tests, when available, will be helpful.

Power spectra for the lateral wind component fluctuation, $v^{\prime}$, at three and six meters height, failed in most cases to agree with Kolmogorov's minus five-thirds law over the range of wave numbers analyzed. Agreement previously was found for the longitudinal. component spectra at normalized wave numbers above $\mathrm{nz} / \mathrm{U}=1.0$ for stable conditions and above $\mathrm{nz} / \overline{\mathrm{U}}=0.2$ for neutral and unstable conditions. For the vertical component, $\mathrm{w}^{\prime}$, the minus five-thirds law was followed above about $\mathrm{nz} / \mathrm{J}=1.2$ for stable conditions and above about 0.7 to 1.0 for neutral and unstable conditions. The $\mathrm{v}^{\text {: }}$ power spectral densities were found in this range of wave numbers to decrease more rapidly with increasing wave number than anticipated from the Kolmogorov theory. This suggests that energy is being removed from the turbulence at wave numbers expected to be in the inertial subrange (where no removal or addition of energy into the turbulence should occur). This unexpected result is confirmed for those cases where wind direction shear data are available, demonstrating the working of the $\overline{\mathrm{V}^{\prime} \mathrm{w}^{\prime}}$ Reynold's stress with the shear, $\delta \overline{\mathrm{v}} / \delta \mathrm{z}$, removing energy from the turbulence to support the gradient of the mean lateral component (or the mean direction shear). The cospectra of the $v^{2} w^{\prime}$
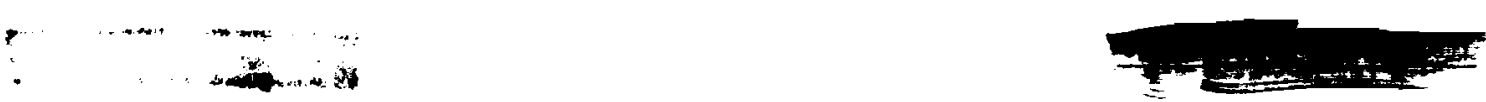
covariance extend to normalized wave numbers near $n z / \widetilde{U}=3.0$ before decreasing to zero, showing that the removal of turbulent energy from the lateral component spectra is still effective over the range of wave numbers in question.

FALIOUT PHENOMENOLOGY - R. J. Engelmann/R。W. Perkins

The ferreting of meteorological and fallout cloud data for shot Smoky continues. Several weather observers noted the position of the fallout cloud in their routine observations and one recorded a very definitive "pilot report" on the cloud position. These reports will allow full verification of the constant-level and the isentropic trajectories being constructed. Extensive pilot balloon (upper wind) data are being used to supplement the radiosonde data.

Calculation of isentropic stream functions from the radiosonde data will be resumed on the 1107 computer, which processes the MIDAS program in two-thirds the machine time of the 7090. The newly available MIMIC programming technique is also being tried to see if further reduction in machine time is possible.

Several atmospheric tracers for use in measuring the washout coefficients of gases and aerosols from the atmosphere by rain and snow have been selected and are being tested in field experiments. The tracers which are presently being tested include iodine, bromine, silver, scandium, cesium and strontium. These elements are measured by neutron activation analysis in snow and rain samples collected in precipitation downwind from the point of release. Radiochemical yields for bromine and the solid trace elements of greater than $98 \%$ are obtained and successful bromine measurements for several field studies have been completed. The natural bromine content observed in snow samples from the east side of the Cascade Mountains was about 1 ppb.

With the drop in airborne fallout radioactivity during the past year, very small amounts of radionuclides peculiar to reactor effluent water have been collected on the air filter of the high volume air sampler in the 300 Area. To verify the suspected source as the reactor effluent water basins, grass and soil samples were collected several hundred feet downwind from a basin and analyzed by multidimensional gamma ray spectrometry. The analyses show the typical reactor effluent water spectrum indicating that a fraction of the effluent water radionuclides are entrained by steam leaving the basins and thus become airborne. Further studies of these airborne radionuclides are planned to measure their magnitude and determine their usefulness as a tracer in atmospheric diffusion and precipitation scavenging studies. 
$\mathrm{HCl}$ is one of the major components released in the exhaust of rockets and its movement in the atmosphere is of interest in connection with this problem and also as a tracer for atmospheric diffusion studies. A spectrophotometric absorption method of analysis for chloride ion was developed which extends the sensitivity for its measirement down to about 10-8 grams. The method is based on an interference reaction in. the formation of silver dithizonate. It involves addition of an excess of standard silver solution to the unknown chloride solution. The excess silver is then complexed with dithizone, extracted into $\mathrm{CCl} 4$ and its concentration determined by its attenuation of the $617 \mathrm{~m} \mu$ absorption peak in the dithizone spectrum.

\section{OPERATION MOUNTAIN IRON (Air Force Sponsored) - C。 L. Simpson}

Twelve diffusion experiments were performed at Soluth Vandenberg, six in the daytime and six at night. One test included concentration measurements with the airborne sensor on the BNT research aircraft. Data reduction of aircraft measurements from two previous tests was completed. Concentrations were determined for 34 sampling traverses through the plume in one test and 25 traverses in the other. Interpolated instantaneous peak concentrations for a number of elevations from 400 to 3000 feet above the sirface at a number of downwind distances to 32 kilometers from the solurce were found for each test. These values demonstrated a sharp decrease of peak concertration with height near the source, as expected, and a considerable flartening of the concentration profile beyond about two kilometers.

\section{RADICLOF TCAL ANT HEALTH PHYSICS}

WHOLE BODY COUNTING $\times$ R. W。 Perkirs

The double scanning shadow shield whole body counter was completed and is being tested. This instrument provides lateral scanning of a subject during the normal iongludinal scan. Preliminary measurements with a masonite phantom and a point sourse of Csl3? show that as the source is moved from the center to the edge of the phantom, at a constant depth, the maximum counting rate change is about 5\%. This car $b \Leftrightarrow$ com. pared with a 100\% change for the standard shadow shield. Further studies will be performed to evaluate and calibrate the instrument for various expected radionuclide distributions which must be measured in the human body。 


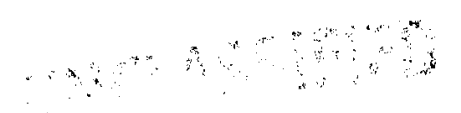

$-12-$

BNWL-24

The Accuracy with which plutonium isotopes can be measured in vivo depends on how well the $\mathrm{X}$-ray to alpha emission rate ratio is known for the isotope mixture being measured. An X-ray/alpha counter was developed, calibrated and is being used to measure the $X$-ray/alpha ratio for the sources used in the initial calibration of the Plutonium Counter. Initial studies indicated that the $X$-ray/alpha ratio for the plutonium isotope mixture being used is about 50\% higher than the widely used value of 0.04 for $\mathrm{Pu}^{239}$.

The electron-capture isotope $\mathrm{Pm} 143$ was prepared, separated from its $N d$ target, and is essentially ready for the human metabolism experiment which is planned jointly with Hanford Occupational Health Foundation. Also, $700 \mathrm{mg}$ of $\mathrm{Np} 237$ was obtained from Isochem and will be irradiated at the ORNL cyclotron to produce the electron-capture isotope $\mathrm{Pu}^{237}$ which will be used in the subsequent metabolism studies. It is planned to begin the experiments with human volunteers immediately on receipt of formal AEC-Battelle approval.

\section{RADIATION DOSTMEIRY - W. E. Wilson}

The sensitivity of the gamma absorbed-dose calorimeter was improved by more than a factor of 6 by reducing the radiant heat loss of the absorbing (graphite) element. The graphite surfaces inside the calorimeter were covered with aluminum foil thereby changing the emissivity. Observed sensitivity and time constant, $320^{\circ} \mathrm{C} /$ watt and 62 minutes, respectively, now agree well with calculated values of $360^{\circ} \mathrm{C} /$ watt and 55 minutes. This performance of the calorimeter is adequate for the gamma dose experiment. Readout for the calorimeter at present is a thermopile monitored with a galvanometer-photocell amplifier. This galvanometer has adequate sensitivity, but needs further refinement in order to get satisfactory stability。

Tests of the $100 \mathrm{cc}$ ion chamber were made in fast neutron radiation fields. With $14 \mathrm{MeV}$ neutrons produced with the positive ion accelerator the ion chamber indicated dose rates of the order of $1 \mathrm{mrad} / \mathrm{sec}$. Ar ion current vs. collection voltage curve was run to obtain the saturation voltage. Inverse $r$ squared runs indicated that the chamber simulates a point detector when distances between source and detector are greater than $20 \mathrm{~cm}$. Beyond $70 \mathrm{~cm}$ the neutron flux density is so low that the detection is marginal, limited by thermally induced variations in the leakage currents. In the 329 Building where the lab is specially air conditioned and temperature changes are short in time and small in magnitude, these variations were less than $\pm 0.5 \times 10^{-1.4} \mathrm{~A}$. However, in the accelerator target room variations in leakage current as much as 20 times larger

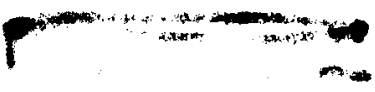


have been observed. Improved stability is important if we are to have a reliable instrument for use at Walla Walla.

Dose measurements made with the tissue-equivalent spherical proportional counter were compared with doses calculated from neutron flux as determined with the precision long counter and first collision dose curves given in NBS Handbook 63. The preliminary results indicated a systematic difference between these two ways of evaluating dose for monoenergetic neutrons. The dose distribution in event size, $D(Y)$, was measured for $16 \mathrm{MeV}$ neutrons. A significant contribution to the dose by heavy recoils is evident in the distribution since energies greater than the maximum energy loss by recoil protons of $100 \mathrm{keV}$ per micron were observed. The graphite used in the carbon-walled spherical counter was found to be much too porous to operate at pressures below atmospheric. It is now being enclosed in an aluminum container and the same atmosphere will be maintained both inside and outside the chamber. This is particularly important at low proton energies where a foil would introduce considerable uncertainty in proton energy。

\section{FILM DOSIMETRY CALIBRATION LABORATORY STUDY - C.M.Unruh}

A detailed schedule for completing this project was issued. This schedule defines the responsibility for each item and an expected completion date.

A letter was drafted that will be sent to government and commercial film dosimeter services enlisting their participation in developing the performance criteria. Film dosimeters will be obtained from each of the services who wish to participate, exposed by Battelle-Northwest to known types, spectra and levels of radiation, and sent to the processors for evaluation. The results will then be analyzed, and criteria developed by Battelle-Northwest Statistical Group. Since we are planning to visit as many of the participating organizations as possible during this fiscal year, we are asking the services to respond to this letter as early as possible.

Comments were issued on the National Sanitation Foundation Standard No. 16 relating to film badge processing. The major criticism of this standard was directed toward the performance criteria adopted. These criteria are based on a single point and can lead to some ambiguous conclusions. For instance, a film processor can have all of his error factors except one lie within the acceptable percentage error limit and not be certified, and another film processor can have one of his error factors lie outside the percentage error limit and be certified. These data need a more thorough review before a final report can be issued. 


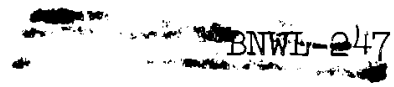

Fifty percent of the Hanford film dosimeter calibration data used to establish the number of film dosimeter calibration results needed from each processing service were placed on punched cards. This key punching project is scheduled for completion in April.

\section{RADIATION INSTRUMENTS}

\section{RADIATION INSTRUMENTS - G. C. FuIlmer}

Following replacement of the amplifier and scaler, successful operation was achieved with the three-detector, whole body rodent counting system. Inhaled quantities of both Pu238 and Pu239 are being measured at the desired accuracy level, where the normal background counting rate is approximately 20 counts/min at the counter location.

Modifications to the transmitter circuits have improved the animal physiological function telemetry system developed for use with free ranging larger animals such as sheep, to the point of readiness for extended field testing. Previous problems of overmodulation have been resolved and proper signal levels are now being obtained with 10-30 $\mathrm{mV}$ for temperature, 0-50 mV for respiration, and 20-30 mV for blood pressure measurement. Proper signal mixing, using discriminators, is being obtained with minimum crosstalk between channels. The new blood pressure transducer demonstrated compatibility with the incorporated bridge circuitry. A second circuitry model transmitter, using a direct-coupled differential amplifier for use with a different bridge circuit, was designed and will be employed in later tests. Temperature and stability testing was initiated on the new circuitry, and general field tests will commence upon delivery of the ordered FM tuners.

Satisfactory data were obtained in two further experiments with the Algae Radionuclide Uptake Monitor, and except for minor water leakage problems with the detectors, routine operation is being achieved. The water leakage problem will be avoided through elimination of the underwater cable connectors.

Special shielding was installed around the alpha energy analysis air monitor, used during radionuclide inhalation experiments with canines, to reduce the radio frequency interference problems, which are apparently caused by nearby electrostatic precipitators. The effectiveness of the improvements will be tested during the next series of inhalation experiments. 
Engineering modifications to a low-noise preamplifier being used with the solid state detector spectrometry system will permit incorporation of a cooled, field effect transistor (FET) amplifying stage. The change also provides a voltage-sensitive (rather than charge-sensitive) input and provides both adjustable time constant and gain control. These changes, now being incorporated, are expected to reduce the system noise levels, especially important in the high resolution spectrometry work for which this system is intended.

Fabrication progressed on the experimental Mixed Neutron-Gamma Dose Rate instrument which will utilize lithium-foil covered surface barrier diodes implanted in polyethylene moderator for neutron detection. The neutron detector and electronics channel are completed, and most of the requirements for the gamma channel have been established and are being fabricated and assembled. The required battery charger was completed, and design of the range-changing circuitry (reed relays) was reviewed and established.

The infrared sources and receptors for the Rodent Activity Monitor performed properly during mockup configuration testing with the caged rodent. The rodent appeared to be unaffected by the experimental apparatus; however, some heating of the cage volume (about a $3^{\circ} \mathrm{F}$ gradient across the cage) was noted due to the incandescent bulbs behind the infrared filter lenses, indicating that infrared sources with less total heat output would be desirable.

Both an orifice flow meter and a venturi-tube flow meter demonstrated applicability for measurement of the tidal volume of air exhaled by canines during inhalation experiments. For flow rates of about $150 \mathrm{cc} / \mathrm{sec}$ and a room temperature of $70^{\circ} \mathrm{F}$, each meter provided a reading of about $0.6 \mathrm{~cm}$ of water in a U-tube. At higher flow rates, the venturi approach should be superior. An integrator, for use with the sensor, was designed and tested for stability.

\section{RADIOLOGICAL CHEMISTRY - R. W. Perkins}

An 11 in. diam. by 6. in. thick detector for multidimensional gammaray spectrometry was assembled and is being tested. This instrument wi.l工 be the most sensitive method by far for the measurement of many radionuclides either alone or in complex mixtures. It will be used mainly in defining radionuclide behavior and in following natural tracers through environmental processes. 
Background measurements from 0 to $10 \mathrm{MeV}$ with large NaI(TI) crystals have characteristically shown a pair of peaks at 6.1 and $6.6 \mathrm{MeV}$. These peaks evidently result from neutron capture in the crystal or its shielding and are reduced to one-half when 4 in. of $5 \%$ boron-polyethylene is placed between the detector and its shield. The Compton response associated with these peaks is responsible for a substantial part of the background at lower energies of interest in gamma ray spectrometry and reduction of this interference will further improve the sensitivity of lowbackground gamma ray spectrometry.

In continuing the study of $\mathrm{Fe}^{55}$ body burdens, 175 samples of blood from the King County blood bank in Seattle were analyzed. The general observations were that females contained more Fe55 than males, older people contained more than younger people, and that men over $170 \mathrm{lbs}$. had a higher Fe 55 concentration in their blood than those under 170 lbs. The average body burden for females was $32.6 \mathrm{nCi}$ while that for males was $23.9 \mathrm{nCi}$. Similar studies now under way in Eastern Washington are showing Fe 55 body burdens for males comparable to those in the Seattle area but the body burdens for females are lower than for males. 
4 


\section{DISTRIBUTION}

Copy Number

1

$2-3$

4

5

$6-7$

8

9

10

11

12

13

14

15

16

17

18

19

20

$21-22$

23

24

25

$26-27$

$28-29$

30

32

33

$34-35$

$36-37$

38

$39-41$

42

43

44

45

46

47

48

49

$50-54$

$55-56$

$57-58$

59

60

61
Battelle-Northwest

F. W. Albaugh

W. J. Bair

C. A. Bennett

J. J. Cadwell

W. J. Clarke

F. G. Dawson

D. R. de Halas

R. F. Dickerson

W. L. Dotson

C. E. Elderkin

R. J. Engelmann

S. L. Fawcett

J. J. Fuquay

R. F. Foster

G. C. Fullmer

W. A. Haney

H. H. Harty

F. P. Hungate

E. R. Irish

R. L。Junkins

D. R. Kalkwarf

A. R. Keene

H. A. Kornberg

W. H. Matchett

R. E. Nakatani

C. E. Newton

J. M. Nielsen

R. F. Palmer

J. L. Palotay

H. M. Parker

R. S. Paul

D. W. Pearce

R. W. Perkins

W. D. Richmond

W. C. Roesch

W. Sale

P. T. Santilli

L.C. Schwendiman

C. L. Simpson

W. A. Snyder

M. F. Sullivan

R. C. Thompson

C. R. Tipton

C. M. Unruh

M. T.Walling 


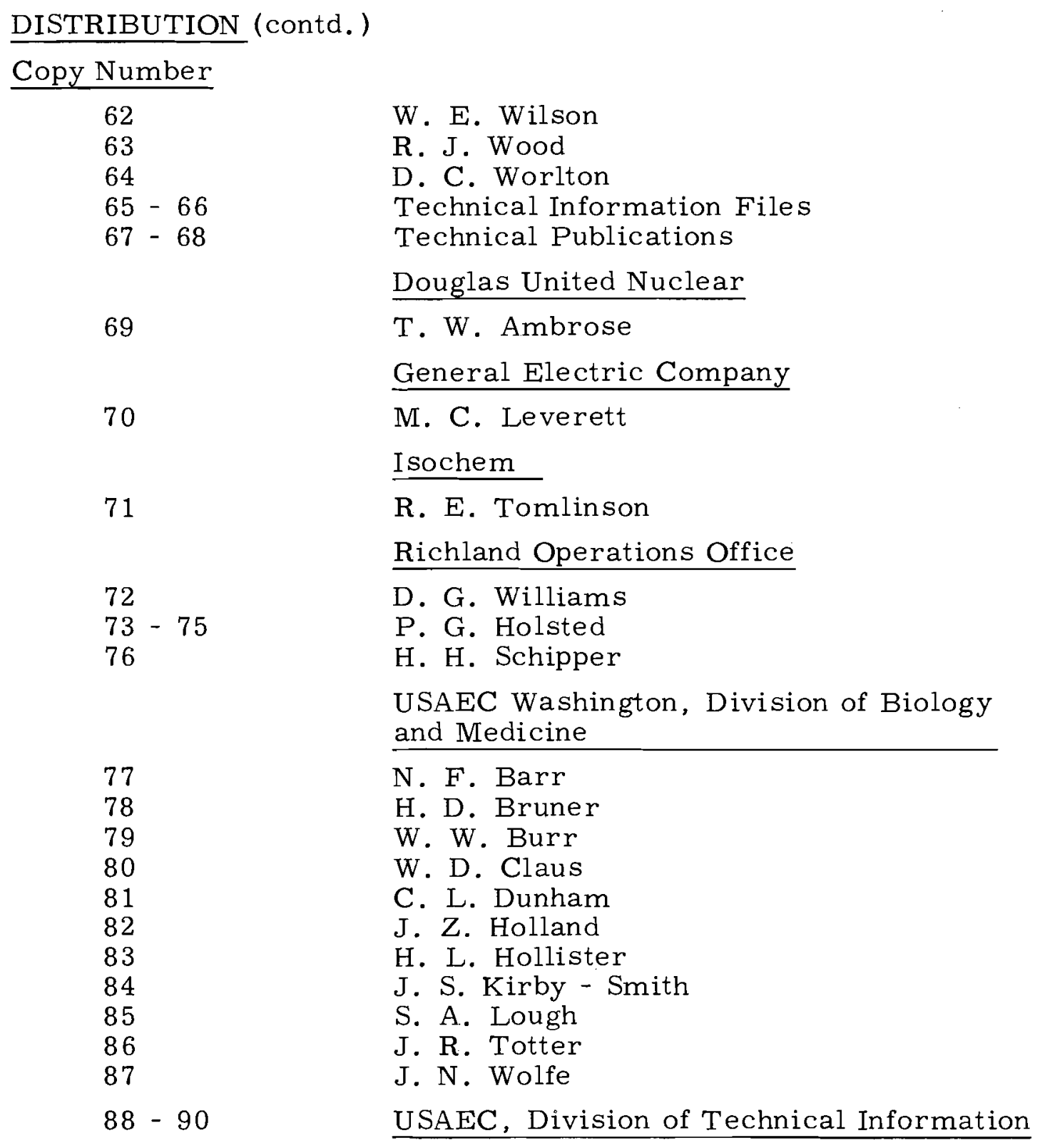

